\title{
Method for maximising measurements of muscular pulmonary arteries
}

\author{
JUNE M FERNIE, ${ }^{*}$ D LAMB† \\ From the *Institute of Occupational Medicine, Edinburgh, and the †Department of Pathology, University of \\ Edinburgh Medical School, Edinburgh
}

SUMMARY Using a digitiser for assessing the media and intima of muscular pulmonary arteries, we have previously shown that the most sensible measurements are those of medial and intimal area and that artery size should be defined in terms of the total length of internal elastic lamina. These measurements do not vary with the collapse or constriction of the artery. A cross sectional cut and a well defined internal elastic lamina are essential for measurement using our technique.

This study explores methods for obtaining the above three measurements for cross sectionally cut arteries with an ill defined internal elastic lamina, with a view to increasing the number of arteries measured. The methods were tested on three subjects, using arteries for which the true values of the three variables were known.

Acceptable estimates of medial and intimal area could be obtained by simply delineating the boundaries of the intima and media and ignoring the crinkles in the elastic laminae. It was also found that muscular pulmonary arteries may not be uniformly collapsed or constricted round th 8 circumference of their walls and that the overall degree of collapse or constriction seemed to be affected by the size of the artery. An acceptable estimate of the total length of an internal elastiōe lamina was most readily obtained by multiplying the length of the boundary between intima and media by a crinkle factor based on an optical assessment of the amount of crinkling in that internal elastic lamina.

Using a semiautomatic digitising system, we recently developed new techniques for the measurement of the area of the media ${ }^{1}$ and intima ${ }^{2}$ in muscular pulmonary arteries that had not been distended by an injection medium. These ${ }^{12}$ and other similar techniques $^{3-8}$ define the size of the artery in terms of the length of the internal elastic lamina, a measurement that does not vary with the constriction or collapse of the artery.

Two critera must be satisfied before an artery can be measured by our method: the artery must be cut in cross section and it must have a well defined internal elastic lamina. Therefore, although very accurate measurements are obtained, only a small proportion of the total artery population can be measured. ${ }^{1}$ We showed that embedding tissue in glycol methacrylate in preference to paraffin helps to increase the number of arteries considered to be measurable ("digitisable"). ${ }^{9}$

Nevertheless, sometimes only paraffin embedded tissue is available or only one or two tissue samples

Accepted for publication 19 August 1985 such as biopsy specimens. On these occasions we believed that it would be advantageous to increase the number of arteries measured, especially if this could be done with a minimum loss of accuracy. We thought that this might be possible while continuing to define artery size in terms of total length of internal elastic lamina. We aimed to obtain measurements of 3 medial and intimal area for cross sectionally cut 8 "undigitisable" arteries by simply delineating the $₹$ boundaries of the media and intima and ignoring the 을 crinkles in the elastic laminae. In addition, we envisaged that there would be three possible ways of estimating the length of an internal elastic lamina - that is, multiplying the length of the boundary between the $\mathrm{N}$ intima and media by a factor based on:

1 An optical estimate of the degree of crinkling (collapse or constriction) in that internal elastic lamina, using the crinkle grading method.

2 The measured amount of crinkling in a segment of $\stackrel{?}{?}$ that internal elastic lamina, assuming this to be 0 representative of the whole, using the segmental crinkle factor method. 
3 The measured amount of overall crinkling in the internal elastic laminae of the "digitisable" arteries, using the mean crinkle factor method.

These methods for estimating medial and intimal areas and total lengths of internal elastic laminae were tested using arteries for which the true values of the variables were known. This paper describes the results.

\section{Material and methods}

\section{SUBJECTS}

One lung from each of the three subjects was studied. Their ages were 51,80 , and 81 years. With respect to cardiopulmonary pathology, one subject had a small peripheral carcinoma in the lung, the two others showed no specific abnormalities. These three subjects were chosen for inclusion in the study because their muscular pulmonary arteries showed considerable variation in the degree of medial hypertrophy, intimal thickening, and constriction or collapse present.

The lungs were fixed by inflation with formol saline, and 12 tissue blocks were randomly selected from the two most lateral sagittal slices of each. These blocks were embedded in glycol methacrylate, sectioned, and stained as described previously. ${ }^{19}$

\section{METHOD OF MEASUREMENT}

Measurements of several variables of muscular pulmonary arteries were obtained directly from histological sections using a light microscope with a camera lucida attachment and graphic digitising systems 1 equipment. This equipment, which has been described in detail, ${ }^{12}$ was supplied by Graphic Information Systems.

The histological sections from the three subjects were scanned, and each muscular pulmonary artery cut in cross section with a well defined internal elastic lamina, identified by the coordinates (Vernier scale readings) at which it lay in the centre of the field of view. Measurements of these arteries (termed "digitisable") were then made using program 1 and the "trace lengths" program.

Program 1 was specifically designed to measure several variables of digitisable muscular pulmonary arteries; those pertinent to the present study were intimal area, medial area, lumen circumference, and lengths of internal and external elastic laminae. Two sets of measurements were made on each artery. Initially, the artery was measured according to the standard procedure for digitisable arteries - that is, the boundary between the lumen and intima was traced (termed lumen circumference), and the total lengths of the internal and external elastic laminae were obtained by tracing the crinkles in the laminae (Fig. 1a). All coordinates "activated" on the digitising board during these three measurements were recorded and analysed by the microcomputer. Medial area was calculated as the area enclosed by the external elastic lamina less the area enclosed by the internal elastic lamina. Similarly, intimal area was the area enclosed by the internal elastic lamina less the area enclosed by the lumen circumference. The measurements obtained by this procedure were designated intimal area (1), medial area (1), lumen circumference, internal elastic lamina (1), and external elastic lamina (1) (Fig. 1a). The artery was then measured again, ignoring the crinkles in the internal and external elastic laminae and simply delineating the boundaries of the intimal and medial components. The measurements obtained by this procedure were designated intimal area (2), medial area (2), lumen circumference, internal elastic lamina (2), and external elastic lamina (2) (Fig. 1b). Although internal elastic lamina (2) and external elastic lamina (2) were not strictly measurements of either the internal or external elastic lamina, they were labelled as such for convenience.

This paper is specifically concerned with the measurements of medial area, intimal area, and size of artery (length of internal elastic lamina). As the first of the two techniques just described produces accurate measurements for all three variables we referred to it as the "standard" technique. In the second technique the measurements of medial and intimal area were approximations, and the length of the boundary between intima and media only was measured. This technique was termed the "abridged" technique. Several other measurements were required so that the three proposed methods for estimating the total length of an internal elastic lamina could be tested.

The crinkle grading method required an optical estimate of the amount of crinkling in each internal elastic lamina. This was done on a scale of 0 to 4 . Fig. 2a-d shows typical examples of grades 1 to 4 . Grade 0 is not shown: as one might imagine it represents an internal elastic lamina that does not have crinkles, and this is rarely seen in uninjected arteries.

The segmental crinkle factor method necessitated that the degree of crinkling was measured in different segments of each internal elastic lamina. This was done using the trace lengths program. Using an eye piece graticule composed of eight radiating spokes, each artery was orientated so that its internal elastic lamina was subdivided into eight roughly equal segments (Fig. 3). Initially, the total length of each segment of the internal elastic lamina was obtained by tracing the crinkles (Fig. 3). These trace lengths were designated $A B(1), B C(1), C D(1)$ and so on. A further set of measurements was then made; this time the 

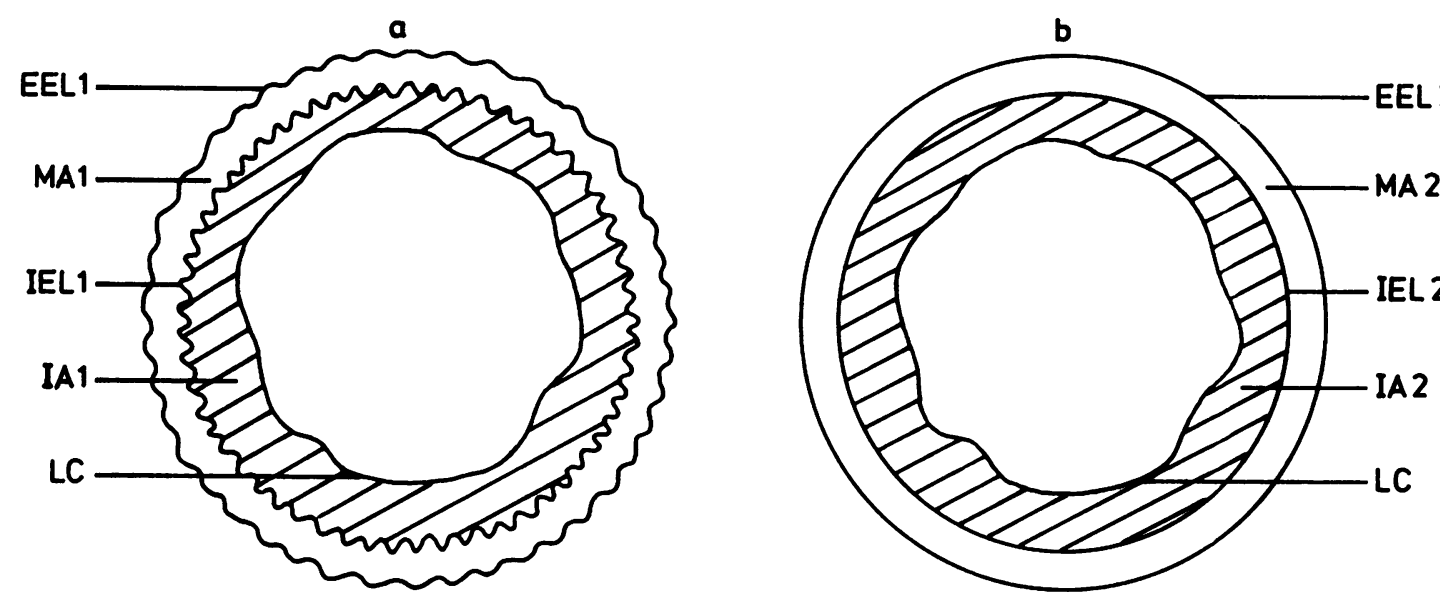

Fig. 1 Diagrammatic representation of muscular pulmonary artery indicating some measurements obtained using standard (a) and abridged (b) technique associated with program 1. EEL = length of external elastic lamina, MA = medial area, $I E L=$ length of internal elastic lamina, $I A=$ intimal area, $L C=$ circumference of lumen.

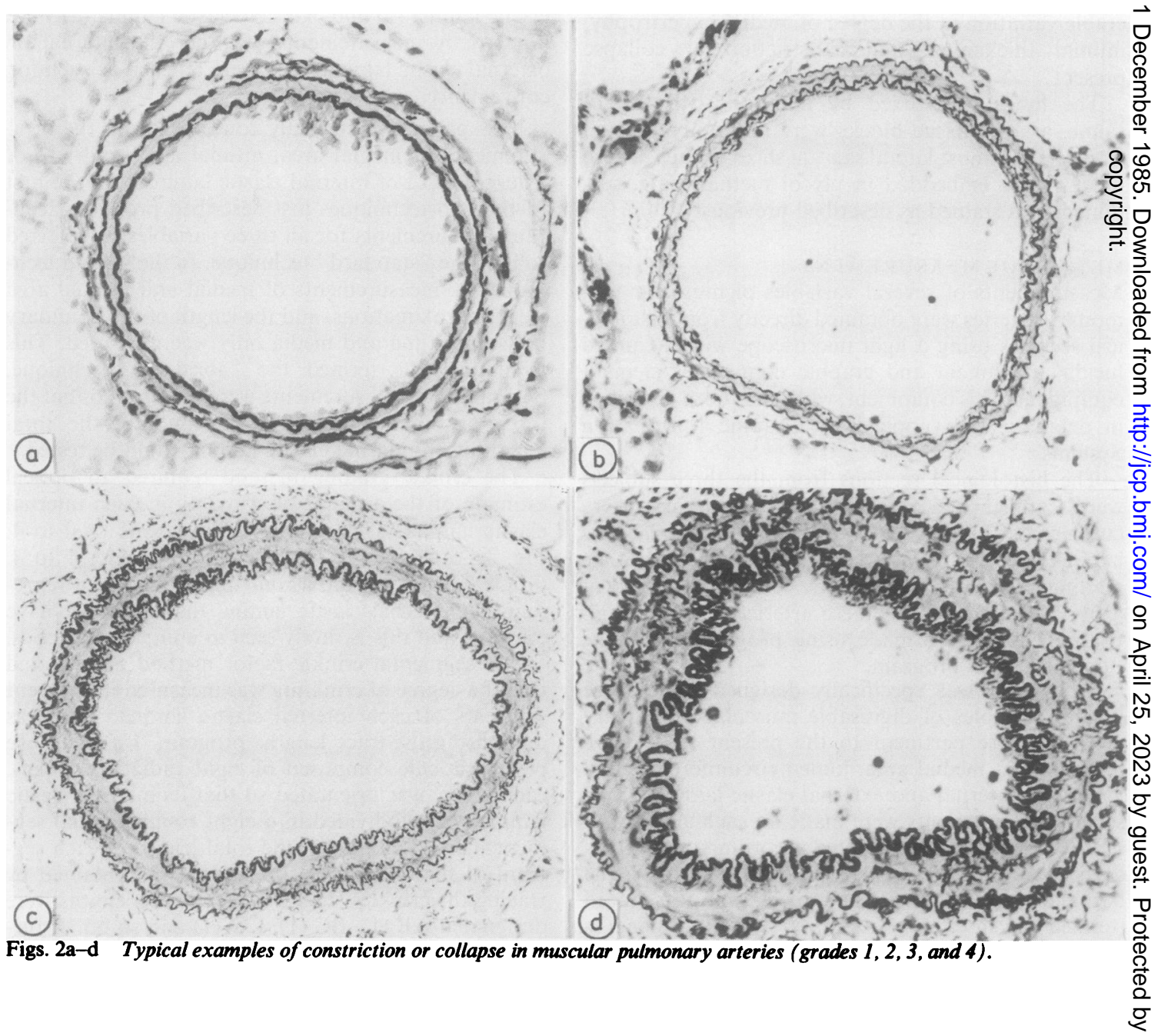


crinkles in the elastic lamina were ignored, and instead the boundary between the intima and media was delineated. These trace lengths were designated AB (2), BC (2), CD (2) and so on (Fig. 3). Segmental crinkle factors were obtained by simply dividing $A B(1)$ by $A B(2), B C(1)$ by $B C(2)$ and so on.

The mean crinkle factor method necessitated that the overall degree of crinkling in each internal elastic lamina was measured (for the digitisable arteries). This was easily obtained from the measurements made, using the standard and abridged techniques, by dividing the total length of the internal elastic lamina (IEL (1)) by the length of the boundary between intima and media (IEL (2)).

\section{ANALYSIS OF DATA}

The "simple regressions" program was used to determine the relation between any two variables. Various functions, linear and non-linear, were fitted to the data and the program selected the one giving the best fit.

The "intima index" program enabled the intimal area of arteries measured using program 1 to be expressed as a proportion of the area enclosed by the internal elastic lamina in its theoretically unwrinkled state. Values for the intima index ranged from $>0$ to $\leqslant 1$, indicating minimal through to total occlusion of the artery lumen.

All four programs used were written in BASIC and supplied by Graphic Information Systems, with the exception of the intima index program, which may be obtained from the Institute of Occupational Medicine.

\section{Results}

COMPARISON OF AREA MEASUREMENTS USING THE STANDARD AND ABRIDGED TECHNIQUES

The measurements of medial and intimal area obtained, using the two techniques, were compared. Table 1 indicates that there was a closer agreement between measurements of medial area than between measurements of intimal area (cases 1 and 2). The abridged technique produced measurements of medial area that were within $10 \%$ of the exact values for all but one $(2 \%)$ of the arteries (case 1). In seven $(14 \%)$ of the arteries, however, the measurements of intimal area produced by the abridged technique deviated by more than $10 \%$ from the exact values. The corresponding figures were two $(5 \%)$ and five $(13 \%)$ (case 2). The reverse was true for case 3 (Table 1): none of the arteries measured showed differences between the measurements of intimal area obtained by the standard and abridged techniques in excess of $10 \%$. In contrast, six $(15 \%)$ of the arteries measured showed differences between the measurements of

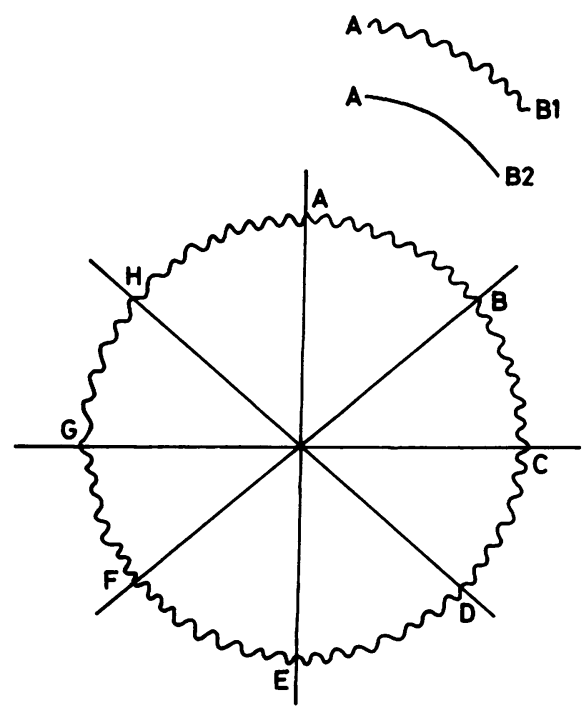

Fig. 3 Diagrammatic representation of an internal elastic lamina indicating the measurements made using the trace lengths program.

medial area in excess of $10 \%$. Case 3 showed the most severe intimal thickening of all the subjects studied. We concluded that agreement between area measurements derived by the standard and abridged techniques was closer for whichever structural component (media or intima) encompassed the bigger area in that artery.

\section{COMPARISON OF DIFFERENT METHODS OF ESTIMATING THE LENGTH OF AN INTERNAL ELASTIC LAMINA}

The crinkle grading method After each artery was optically graded for degree of constriction or collapse on a five point scale we calculated how much longer, on average, was the total length of the internal elastic lamina (IEL (1)) compared with the length of the boundary between the intima and media (IEL (2)) for

Table 1 Comparison of standard and abridged techniques for measuring medial and intimal areas

\begin{tabular}{lllr}
\hline $\begin{array}{l}\text { Case } \\
\text { No }\end{array}$ & $\begin{array}{l}\text { No arteries } \\
\text { measured }\end{array}$ & \multicolumn{1}{l}{ Area } & \\
\cline { 2 - 4 } & & Intima & Media \\
\hline 1 & 50 & $20^{*}(7)$ & $7(1)$ \\
2 & 39 & $20(5)$ & $6(2)$ \\
3 & 41 & $9(0)$ & $15(6)$ \\
\hline
\end{tabular}

* Number of arteries in which measurements obtained with abridged technique differed by $5 \%$ or more from those obtained with the standard technique (figures in parentheses are number of arteries in which differences were $10 \%$ or greater. 
arteries with a crinkle grade of $0,1,2,3$, and 4 in each subject. We found that the total length of the internal elastic lamina (IEL (1)) was $23 \%, 32 \%$, and $47 \%$ longer than the length of the boundary between intima and media (IEL(2)) in arteries graded 1, 2, and 3 , respectively (case 1). No arteries were graded 0 or 4 . Treating each artery as an undigitisable artery, we then tried estimating the length of the internal elastic lamina by multiplying the measurement IEL(2) by the mean value of $23 \%, 32 \%$, or $47 \%$, depending on the crinkle grade assigned to that artery. Table 2 shows the estimated values for the lengths of the internal elastic laminae in the arteries (case 1), together with the measured values and the percentage errors incurred. In only $13(26 \%)$ of the arteries did the estimated value differ by more than $10 \%$ from the measured value. The corresponding figures were $21 \%$ and $32 \%$, respectively, for cases 2 and 3 .

On the basis of these results we concluded that the crinkle grading method for estimating the length of an internal elastic lamina was a practical possibility. The segmental crinkle factor method Table 3 lists the range of segmental crinkle factors observed in the arteries of case 1, together with the overall artery crinkle factors. The degree of constriction or collapse in any artery was not uniform round the artery wall (Table 3). Several arteries showed an increase in crinkle factor by as much as $100 \%$ between the least and most constricted segments of the internal elastic lamina. Similar trends were evident in the other two subjects studied.

The considerable range in values for segmental crinkle factors led us to conclude that the total length $\stackrel{8}{\overrightarrow{3}}$
of an internal elastic lamina could not be approxi- 을 mated by multiplying the length of the boundary $\Rightarrow$ between intima and media (IEL (2)), by a crinkle fac- of tor derived from any one segment of that internal elastic lamina.

The mean crinkle factor method For all subjects the overall crinkle factor of each artery was plotted against its size (defined as IEL (1)). Fig. 4 shows the in results for case 1 only, and illustrates two very important points. Firstly, for arteries of a similar size there is some variation in the overall crinkle factors observed. This difference in crinkle factor between arteries of a similar size, however, is much less pronounced than that between segments of a single $\omega$ artery. Secondly the crinkle factor tends to increase, the larger the artery, indicating that the larger arteries are more constricted. This increase in crinkle factor with a corresponding increase in size of artery was seen in all three cases, although to varying extents. In effect, these findings ruled out the possibility that the total length of an internal elastic lamina could be estimated by multiplying the length of the boundary between intima and media by a mean crinkle factor based on all measured digitisable arteries.

Up to this point we had been concerned with assessing the errors incurred in the measurement of medial and intimal areas in the individual artery usin the abridged technique; these errors were generall less than $10 \%$. We had also compared three different methods of estimating the length of an internal elastic lamina, one of which (the crinkle grading method)

Table 2 Estimated* and measured values for length of internal elastic lamina (IEL) (case 1), together with percentage errors

\begin{tabular}{|c|c|c|c|c|c|}
\hline $\begin{array}{l}\text { Estimated } \\
I E L \text { (I) }\end{array}$ & $\begin{array}{l}\text { Measured } \\
I E L(1)\end{array}$ & $\%$ error & $\begin{array}{l}\text { Estimated } \\
\text { IEL (1) }\end{array}$ & $\begin{array}{l}\text { Measured } \\
\text { IEL (1) }\end{array}$ & $\%$ error \\
\hline $\begin{array}{r}754 \cdot 1 \\
1764 \cdot 8 \\
737 \cdot 7 \\
452 \cdot 6 \\
1331 \cdot 4 \\
2512 \cdot 8 \\
1051 \cdot 3 \\
423 \cdot 1 \\
479 \cdot 7 \\
2414 \cdot 8 \\
989 \cdot 5 \\
461 \cdot 5 \\
677 \cdot 3 \\
890 \cdot 4 \\
519 \cdot 9 \\
1404 \cdot 7 \\
1519 \cdot 4 \\
828 \cdot 2 \\
2632 \cdot 2 \\
563 \cdot 5 \\
639 \cdot 3 \\
697 \cdot 1 \\
1244 \cdot 6 \\
1525 \cdot 6 \\
976 \cdot 7\end{array}$ & $\begin{array}{r}818 \cdot 5 \\
1983 \cdot 3 \\
801 \cdot 3 \\
489 \cdot 7 \\
1368 \cdot 3 \\
3129 \cdot 4 \\
1027 \cdot 2 \\
420 \cdot 9 \\
472 \cdot 4 \\
2373 \cdot 7 \\
971 \cdot 6 \\
434 \cdot 9 \\
689 \cdot 6 \\
881 \cdot 4 \\
523 \cdot 0 \\
1421 \cdot 4 \\
1604 \cdot 5 \\
824 \cdot 3 \\
2943 \cdot 4 \\
552 \cdot 6 \\
590 \cdot 9 \\
629 \cdot 6 \\
1337 \cdot 0 \\
1680 \cdot 3 \\
993 \cdot 7\end{array}$ & $\begin{array}{r}-7.9 \\
-11.0 \\
-7.9 \\
-7.6 \\
-2.7 \\
-19.7 \\
+2.4 \\
+0.5 \\
+1.5 \\
+1.7 \\
+1.8 \\
+6.1 \\
-1.8 \\
+1.0 \\
-0.6 \\
-1.2 \\
-5.3 \\
+0.5 \\
-10.6 \\
+2.0 \\
+8.2 \\
+10.7 \\
-6.9 \\
-9.2 \\
-1.7\end{array}$ & $\begin{array}{r}1788 \cdot 1 \\
1524 \cdot 4 \\
1359 \cdot 8 \\
456 \cdot 2 \\
1424 \cdot 1 \\
1293 \cdot 8 \\
518 \cdot 2 \\
1067 \cdot 8 \\
529 \cdot 6 \\
1038 \cdot 7 \\
1551 \cdot 4 \\
2058 \cdot 0 \\
1903 \cdot 8 \\
462 \cdot 7 \\
1038 \cdot 8 \\
340 \cdot 7 \\
1124 \cdot 1 \\
405 \cdot 1 \\
1505 \cdot 6 \\
957 \cdot 1 \\
530 \cdot 2 \\
447 \cdot 6 \\
1513 \cdot 5 \\
943 \cdot 0 \\
643 \cdot 1\end{array}$ & $\begin{array}{r}1984 \cdot 1 \\
1568 \cdot 6 \\
1343 \cdot 7 \\
411 \cdot 6 \\
1585 \cdot 8 \\
1293 \cdot 6 \\
489 \cdot 1 \\
1017 \cdot 6 \\
500 \cdot 9 \\
888 \cdot 6 \\
1362 \cdot 7 \\
2211 \cdot 7 \\
1791 \cdot 1 \\
472 \cdot 6 \\
1041 \cdot 6 \\
328 \cdot 0 \\
1072 \cdot 5 \\
414 \cdot 7 \\
1507 \cdot 4 \\
892 \cdot 9 \\
474 \cdot 8 \\
422 \cdot 4 \\
1700 \cdot 2 \\
810 \cdot 3 \\
566 \cdot 7\end{array}$ & $\begin{array}{l}-9.9 \\
-2.8 \\
+1.2 \\
+10.8 \\
-10.2 \\
+0.02 \\
+5.9 \\
+4.9 \\
+5.7 \\
+16.9 \\
+13.8 \\
-6.9 \\
+6.3 \\
-2.1 \\
-3.3 \\
+3.9 \\
+4.8 \\
-2.3 \\
-0.1 \\
+7.2 \\
+11.7 \\
+6.0 \\
-11.0 \\
+16.4 \\
+13.5\end{array}$ \\
\hline
\end{tabular}

*Estimated by the crinkle grading method. 
Table 3 Range of segmental crinkle factors in each artery (case 1), together with overall artery crinkle factor

\begin{tabular}{|c|c|c|c|}
\hline $\begin{array}{l}\text { Range of segmental } \\
\text { crinkle factors }\end{array}$ & $\begin{array}{l}\text { Crinkle factor of } \\
\text { artery }\end{array}$ & $\begin{array}{l}\text { Range of segmental } \\
\text { crinkle factors }\end{array}$ & $\begin{array}{l}\text { Crinkle factor of } \\
\text { artery }\end{array}$ \\
\hline $\begin{array}{l}1 \cdot 13-1.47 \\
1.28-1.83 \\
1 \cdot 12-2.01 \\
1 \cdot 18-1.82 \\
1 \cdot 11-1.85 \\
1.22-1.96 \\
1.36-1.95 \\
1 \cdot 14-1.77 \\
1 \cdot 10-1.53 \\
1.03-2.00 \\
1.32-2.18 \\
1.03-2.01 \\
1.01-1.92 \\
1.20-2.34 \\
1.24-2.00 \\
1 \cdot 15-1.96 \\
1.27-1.86 \\
1 \cdot 13-1.84 \\
1.19-1.95 \\
1 \cdot 11-1.76 \\
1.05-1.58 \\
1.20-1.47 \\
1.18-1.81 \\
1.41-1.81 \\
1.32-2.03\end{array}$ & $\begin{array}{l}1.34 \\
1.48 \\
1.43 \\
1.43 \\
1.51 \\
1.64 \\
1.44 \\
1.22 \\
1.30 \\
1.30 \\
1.44 \\
1.24 \\
1.34 \\
1.46 \\
1.33 \\
1.49 \\
1.55 \\
1.46 \\
1.64 \\
1.29 \\
1.22 \\
1.19 \\
1.42 \\
1.62 \\
1.50\end{array}$ & $\begin{array}{l}1 \cdot 10-2.15 \\
1.26-2.34 \\
1 \cdot 14-1.96 \\
1.15-1.41 \\
1.46-1.90 \\
1.11-1.79 \\
1.22-1.91 \\
1.29-1.85 \\
1 \cdot 14-1.35 \\
1.26-1.57 \\
1.09-1.38 \\
1.32-2.21 \\
1.25-1.76 \\
1.36-2.10 \\
1.24-2.62 \\
1.15-1.54 \\
1.31-1.86 \\
1.47-1.95 \\
1.06-2.05 \\
1.18-1.81 \\
1.14-1.98 \\
1.16-1.55 \\
1.24-2.67 \\
1.14-1.49 \\
1.12-1.48\end{array}$ & $\begin{array}{l}1.47 \\
1.51 \\
1.45 \\
1.19 \\
1.64 \\
1.32 \\
1.39 \\
1.40 \\
1.16 \\
1.26 \\
1.16 \\
1.58 \\
1.38 \\
1.35 \\
1.47 \\
1.18 \\
1.40 \\
1.35 \\
1.47 \\
1.37 \\
1.18 \\
1.25 \\
1.65 \\
1.26 \\
1.16\end{array}$ \\
\hline
\end{tabular}

produced estimated values that were within $10 \%$ of the actual values for most arteries measured. The problem at this point was how to determine whether the techniques for estimating medial area, intimal area, and length of internal elastic lamina were acceptable or not. We decided that this problem was best solved by investigating the overall correlation

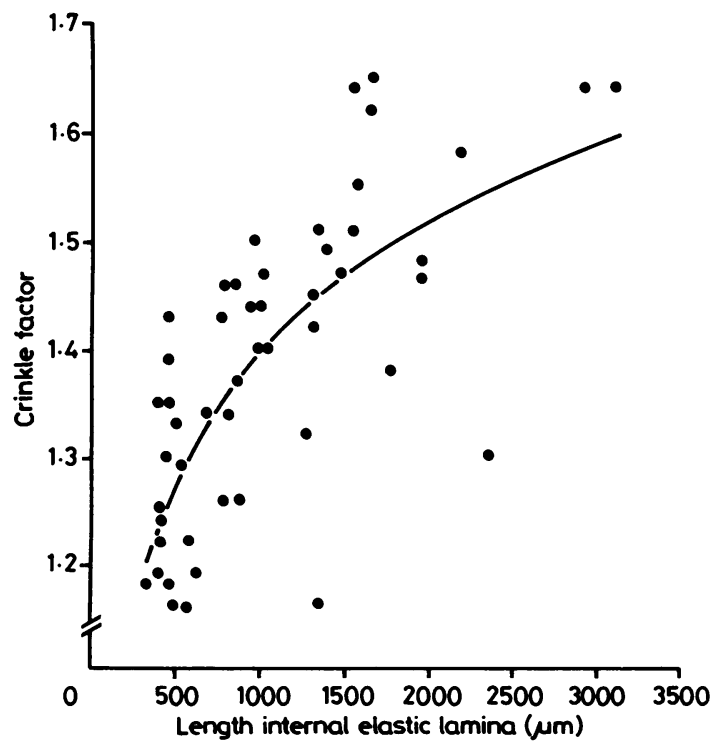

Fig. 4 The relation between artery crinkle factor and size of artery (case 1). between medial area and size of artery and intimal area and size of artery.

\section{THE CORRELATION BETWEEN MEDIAL AREA} AND SIZE OF ARTERY

We have previously shown that the correlation between medial area and size of artery (defined in terms of the length of the internal elastic lamina) generally takes the form $y=A x^{b} .{ }^{9}$ To compare any two sets of data this correlation must be converted to a linear form, and this is best achieved by plotting the square root of the medial area against the length of internal elastic lamina. A comparison of the resulting slopes will then determine whether the correlations are identical or dissimilar.

Using the simple regressions statistical program, we determined for each subject the relation between

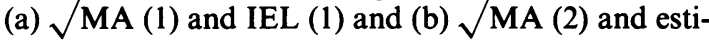
mated IEL (1), as determined by the crinkle grading method. Fig. 5 shows the relations (a) and (b) for case 1. The two relations were virtually identical. The same was true for cases 2 and 3 .

\section{THE RELATION BETWEEN INTIMA INDEX AND} SIZE OF ARTERY

In an earlier study we concluded that the most readily understandable method of expressing patchy intimal change was to calculate a mean intima index for arteries subdivided by size. ${ }^{2}$ An intima index is calculated by dividing the intimal area of an artery by the area enclosed by the internal elastic lamina in its theoretically unwrinkled state, which is required to 


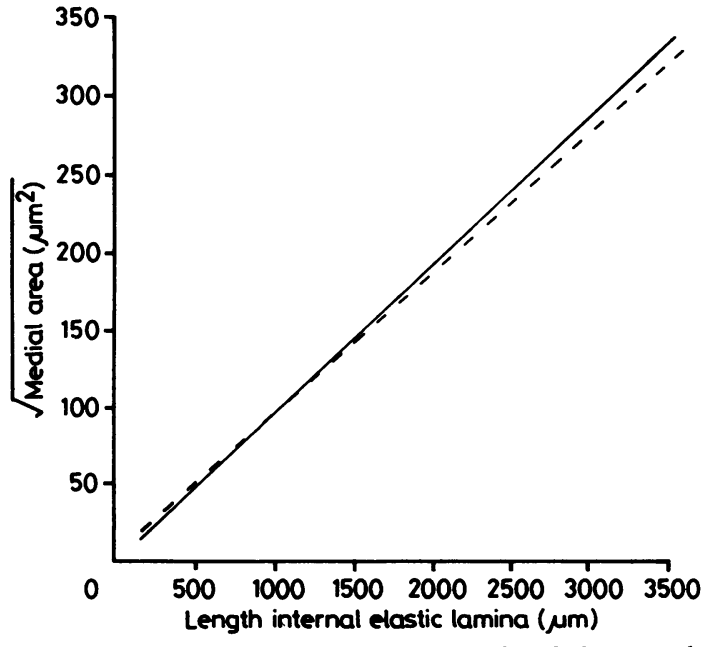

Fig. 5 The relation between square root of medial area and length of internal elastic lamina (case 1). The lines of best fit are:

$$
\begin{gathered}
\text { (-) } \sqrt{M A(1)} v I E L(1) \quad y=7.53+0.10 x, r=0.98 \\
(--) \sqrt{M A(2)} \text { vestimated IEL (1) } \\
y=12.83+0.09 x, r=0.97 \\
\text {-crinkle grading method } \\
M A=\text { medial area, IEL = length of internal elastic lamina. }
\end{gathered}
$$

accommodate differences in the degree of collapse or constriction between arteries.

Intima index $=$ area of intima

area enclosed by internal elastic lamina in
theoretically unwrinkled state
$=$ intimal area/(length of internal elastic
lamina $^{2} / 4 \pi$ )

Values range from $>0$ to $\leqslant 1$, indicating minimal through to total occlusion of the artery lumen.

Two sets of intima indexes were calculated for each artery in the three subjects: for intima index (1) the index was calculated from the measurements IA (1) and IEL (1) and for intima index (2) from IA (2) and estimated IEL (1), as determined by the crinkle grading method.
Arteries were subdivided into three arbitrarily selected groups according to the length of the internal elastic lamina-that is, $<1000,1000-2000$, and $>2000 \mu \mathrm{m}$. Mean intima indexes (1 and 2) were then calculated for arteries in those size groups. Table 4 shows the values for all three subjects. There were no appreciable differences between mean values of intima index (1) and (2) in any size group or subject.

\section{Discussion}

This study established that it is possible, with a minimum loss of accuracy, to obtain measurements of medial and intimal area for muscular pulmonary arteries which, although cut in cross section, have an ill defined internal elastic lamina. More importantly, it is also possible to estimate the total length of the internal elastic lamina in these arteries, providing that some muscular pulmonary arteries with a well defined internal elastic lamina have been measured. The technique used to obtain these measurements is basically an abridged version of a previously described technique ${ }^{12}$ for measuring the cross sectional arteries with a well defined internal elastic lamina.

To determine whether the abridged technique would work it had to be tested using pulmonary arteo ries for which the true values of medial and intimas area and total length of an internal elastic lamina were known. As we had predicted from the outset of the study there were no problems in estimating the medial and intimal areas. Values for medial and intimal areas obtained using the abridged technique were generally within $10 \%$ of those obtained following the standard procedure, and, not surprisingly, there was a closer agreement for whichever structural component encompassed the bigger area.

Two of the methods we thought might work for estimating the length of an internal elastic lamina were intenable and the reasons for this in themselves point to some interesting facts about constriction and collapse after death in pulmonary arteries. Firstly, the degree of constriction or collapse may not be uniform

\begin{tabular}{|c|c|c|c|c|c|c|}
\hline \multirow[t]{3}{*}{ Case No } & \multicolumn{6}{|c|}{ Measured or estimated length of internal elastic lamina } \\
\hline & \multicolumn{2}{|l|}{$<1000 \mu \mathrm{m}$} & \multicolumn{2}{|l|}{$1000-2000 \mu \mathrm{m}$} & \multicolumn{2}{|l|}{$>2000 \mu \mathrm{m}$} \\
\hline & Intima index (1) & Intima index (2) & Intima index (1) & Intima index (2) & Intima index (1) & Intima index (2) \\
\hline $\begin{array}{l}1 \\
2 \\
3\end{array}$ & $\begin{array}{l}0.10(0.03) \\
0.18(0.09) \\
0.19(0.08)\end{array}$ & $\begin{array}{l}0.09(0.03) \\
0.17(0.07) \\
0.19(0.09)\end{array}$ & $\begin{array}{l}0.05(0.02) \\
0.08(0.03) \\
0.08(0.04)\end{array}$ & $\begin{array}{l}0.05(0.01) \\
0.08(0.03) \\
0.08(0.04)\end{array}$ & $\begin{array}{l}0.03(0.006) \\
0.03(0.02) \\
0.05(0.02)\end{array}$ & $\begin{array}{l}0.03(0.005) \\
0.04(0.03) \\
0.06(0.006)\end{array}$ \\
\hline
\end{tabular}
round an arterial wall, and, consequently, it is impossible to estimate the total length of an internal elastic lamina by multiplying the length of the boundary

Table 4 Mean (standard deviation) values of intima index (1) and (2) subdivided by size of arteries in three subjects studied 
between the intima and media by a crinkle factor obtained from part of that lamina.

Secondly, the overall degree of crinkliness in an internal elastic lamina seems to depend on size of artery; the larger arteries are more constricted or collapsed. This was evident in all the subjects studied, although to varying extents. It remains to be seen whether this is a universal feature of muscular pulmonary arteries, but if this is the case then it is yet another reason for not estimating medial hypertrophy $y^{10-14}$ or intimal thickening ${ }^{13-16}$ in uninjected arteries by the commonly used wall thickness methods. Not only will the measurements obtained vary with constriction but arteries of different sizes will be unequally affected.

The remaining method of estimating the length of an internal elastic lamina (the simple optical crinkle grading method) produced what were considered to be acceptable estimates. Determination of the relation between both medial area and intimal area (expressed as intima index) and size of artery, initially using the true values and subsequently the estimated values, showed that both sets of relations were virtually identical. Thus the method of estimating medial and intimal areas was validated, as was the method of estimating the length of an internal elastic lamina. It should be emphasised that when arteries are graded according to degree of constriction or collapse there may well be variations between subjects (and within a subject) in arteries assigned a similar crinkle grade. This was certainly true for the subjects we studied. These variations may be explained by differences in the depth of the crinkles and their distance apart.

There is only one major disadvantage of the described method for measuring cross sectional arteries with an ill defined internal elastic lamina; the increased work entailed in measuring those arteries with a well defined internal elastic lamina. They have to be measured using both the standard and abridged techniques. This disadvantage of the technique is, however, far outweighed by the advantages. The technique facilitates the measurement of medial and intimal areas for all arteries cut in cross section, providing a proportion have a well defined internal elastic lamina. This is of considerable practical importance, especially with regard to the intima for which it is considered advisable to maximise the data obtained to overcome the problems associated with an irregular distribution of intimal abnormality. ${ }^{1718}$ It is also of particular importance in cases in which there is a limited amount of tissue available for assessment-for example, biopsy specimens. Measurement of all cross sectionally cut arteries puts the technique on a par with most of the wall thickness methods ${ }^{10-16}$ in terms of the number of arteries measured. In contrast to these techniques, however, the measurements of the media and intima and size of artery (total length of internal elastic lamina) have the advantage of being unaffected by constriction or collapse of vessels after death of the subject.

We thank the technical staff of the pathology branch, Institute of Occupational Medicine, for photographing the illustrations.

This study was funded by the National Coal Board.

\section{References}

${ }^{1}$ Fernie JM, Lamb D. A new method for quantitating the medial component of pulmonary arteries. The measurements. Arch Pathol Lab Med; 1985;109:156-62.

${ }^{2}$ Fernie JM, Lamb D. New method for measuring intimal component of pulmonary arteries. J Clin Pathol 1985;38:1374-9.

${ }^{3}$ Niwa T. Histometrical studies of the pulmonary artery in sudden death of young and apparently healthy subjects. Tohoku J Exp Med 1971;105:365-80.

${ }^{4}$ Yamaki S, Tezuka F. Quantitative analysis of pulmonary vascular disease in complete transposition of the great arteries. Circulation 1976;54:805-9.

${ }^{5}$ Yamaki S, Wagenvoort CA. Plexogenic pulmonary arteriopathy. Am J Pathol 1981;105:70-5.

${ }^{6} \mathrm{Honda} \mathrm{T}$. Histometrical study of the pulmonary arteries in patients with ventricular septal defect. Nippon Kyobu Geka Gakkai Zasshi 1967;15:162-77.

${ }^{7}$ Kon I. Histometrical studies of pulmonary hypertension with special reference to uremic pneumonitis. Tohoku J Exp Med 1963;79:209-31.

${ }^{8}$ Weibel ER. Morphometry of pulmonary circulation. Progress in Respiration Research 1970;5:2-12.

${ }^{9}$ Fernie JM, McLean A, Lamb D. New method for quantitating the medial component of pulmonary arteries. Factors affecting the measurements. Arch Pathol Lab Med (in press).

${ }^{10}$ Hasleton PS, Heath D, Brewer DB. Hypertensive pulmonary vascular disease in states of chronic hypoxia. Journal of Pathology and Bacteriology 1968;95:431-40.

${ }^{11}$ Heath D, Best PV. The tunica media of the arteries of the lung in pulmonary hypertension. Journal of Pathology and Bacteriology 1958;76:165-74.

${ }^{12}$ Hicken P, Heath D, Brewer DB, Whitaker W. The small pulmonary arteries in emphysema. Journal of Pathology and Bacteriology 1965;90:107-14.

${ }^{13}$ Wagenvoort CA, Wagenvoort N. Age changes in muscular pulmonary arteries. Archives of Pathology 1965;79:524-8.

${ }^{14}$ Hale KA, Niewoehner DE, Cosio MG. Morphologic changes in the muscular pulmonary arteries. Relationship to smoking, airway disease, and emphysema. Am Rev Respir Dis 1980;122:273-8.

${ }^{15}$ Wagenvoort CA, Wagenvoort N. Primary pulmonary hypertension. A pathologic study of the lung vessels in 156 clinically diagnosed cases. Circulation 1970;42:1163-84.

${ }^{16}$ Wagenvoort CA. Pathology of congestive pulmonary hypertension. Progress in Respiration Research 1975;9:195-202.

${ }^{17}$ Wagenvoort CA, Wagenvoort N. Pathology of pulmonary hypertension. New York: John Wiley and Sons, 1977.

${ }^{18}$ Harris P, Heath D. The human pulmonary circulation. 2nd ed. Edinburgh: Churchill Livingstone, 1977.

Requests for reprints to: Dr June M Fernie, Institute of Occupational Medicine, 8 Roxburgh Place, Edinburgh EH8 9SU, Scotland. 